\title{
Removal of perfluorooctane sulfonates from water by a hybrid coagulation-nanofiltration process
}

\author{
Yang Yu ${ }^{\mathrm{a}, \mathrm{b}}$, Changwei Zhao ${ }^{\mathrm{a}, *}$, Ling $\mathrm{Yu}^{\mathrm{b}}$, Pei $\mathrm{Li}^{\mathrm{c}}$, Tao Wang ${ }^{\mathrm{d}}$, Yi Xu ${ }^{\mathrm{a}}$ \\ a State Key Laboratory of Environmental Aquatic Chemistry, Research Center for Eco-Environmental Sciences, Chinese Academy of Sciences, Beijing 100085, China \\ ${ }^{\mathrm{b}}$ Department of Civil and Environmental Engineering, National University of Singapore, 10 Kent Ridge Crescent, Singapore 119260, Singapore \\ ' College of Materials Science and Engineering, Beijing University of Chemical Technology, No. 15 Beisanhuandong Road, Chaoyang District, Beijing 100029, China \\ ${ }^{\mathrm{d}}$ The State Key Laboratory of Chemical Engineering, Department of Chemical Engineering, Tsinghua University, Beijing 100084, China
}

\section{H I G H L I G H T S}

- The removal of PFOS was studied by hybrid coagulation and nanofiltration process.

- The surface charge density and size of the membrane play key role in PFOS removal.

- Coagulation as pretreatment can effectively relieve the NF membrane fouling.

- PFOS can be effectively removed by coagulation and nanofiltration process.

\section{A R T I C L E I N F O}

Article history:

Received 27 October 2015

Received in revised form 30 November 2015

Accepted 15 December 2015

Available online 18 December 2015

\section{Keywords:}

PFOS

Nanofiltration

Coagulation

Humic acid
GR A P H I C A L A B S T R A C T

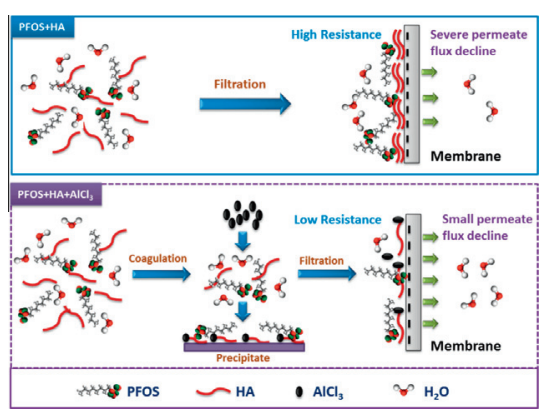

\begin{abstract}
A B S T R A C T
Perfluorooctane sulfonates (PFOS) as a persistent, bioaccumulative and toxic pollutant has been detected in surface water around the world and attracted great attention in recent years. It's important and urgent to develop effective technology to remove PFOS. The effect of coagulation pretreatment on the removal efficiency of PFOS by nanofiltration (NF) was investigated. Two types of NF membranes were used to test the PFOS rejections in three different solutions including DI water, humic acid (HA) solution and coagulation solution. The characterizations such as HA and PFOS accumulation on the membranes, scanning electron microscopy (SEM) and surface $\zeta$ potential analysis of virgin and fouled membranes were conducted to study the separation mechanism. The experimental results showed that PFOS can be partly removed by coagulation. The NF270 membrane exhibited a higher PFOS rejection (>95\%) than the HYDRACORE membrane (40-60\%) in single NF process. The surface negative charge density of both NF membranes reached a minimum value after filtering coagulation effluent, which might be a result of floc adsorption on the membrane surface. Coagulation pretreatment was effective to enhance the PFOS rejection of the NF membranes. In particular, the rejection efficiency of the HYDRACORE membrane increased from $55 \%$ to $86 \%$ at a trans-membrane pressure of $0.4 \mathrm{MPa}$. The SEM images showed that the fouling layer formed by flocs was loose and highly permeable.
\end{abstract}

(c) 2015 Elsevier B.V. All rights reserved.

\footnotetext{
* Corresponding author. Tel.: +86 10 62917207; fax: +86 1062849198 .

E-mail address: zhaocw@rcees.ac.cn (C. Zhao).
}

\section{Introduction}

Perfluorinated compounds (PFCs) have been widely used in the production of fluoropolymers which are often utilized in many industrial, commercial or consumer applications to make surfac- 
tants, fire-fighting foams, lubricants, insecticides, polymer additives and so on. Perfluorooctane sulfonates (PFOS) as one of the typical PFCs have increasingly attracted global concern because of their widespread presence in environmental systems (such as wastewater, surface water, ground water and tap water throughout the world [1]) and in human body. Furthermore, PFOSrelated substances are persistent [2], bioaccumulative [3], and potentially harmful [4]. It is demonstrated that the presence of PFOS even in trace amount may interfere thyroid functions, pancreatic functions, gap junctional intercellular communication, and fatty acid protein binding in the liver [5-7]. Since 2009, PFOS and its related substances have been listed as the first fluorinated persistent organic pollutants and restricted for use in both USA and Europe. In the same year, the USEPA established a Provisional Health Advisory (PHA) of $0.2 \mu \mathrm{g} / \mathrm{L}$ for PFOS in the drinking water.

Studies have reported that the concentration of PFOS in aquatic environments may vary over several orders of magnitude. In the most surface waters, PFOS concentration is measured from 10 to $180 \mathrm{ng} / \mathrm{L}$ level [8-10]. However, higher concentration up to hundreds ng/L and several $\mu \mathrm{g} / \mathrm{L}$ has been detected in the effluent of wastewater treatment plants (WWTPs) [11-14] due to the limiting removal efficiency of PFOS from the current wastewater treatments. The concentration of PFOS in the groundwater collected from military bases can even reach up to $2.3 \mathrm{mg} / \mathrm{L}$ due to the use of aqueous film-forming foams [15]. Thus, it is necessary to develop cost-effective and high-efficiency technologies for removing PFOS from water.

Membrane filtration has been broadly applied in wastewater treatment and drinking water purification due to its highefficiency in the removal of wide range of contaminants. Some studies on the removal of PFCs from semiconductor wastewater using reverse osmosis (RO) or nanofiltration (NF) have been carried out [16,17], where the concentration of PFCs in wastewater is generally higher than $10 \mathrm{mg} / \mathrm{L}$. Typically, NF membrane has a higher rejection to water contaminants than microfiltration (MF) and ultrafiltration (UF) membranes and a higher water flux than RO membrane. Thus, the applications of NF towards the removal of trace amount of organic matters and inorganic contaminants have been extensively studied [18-20]. As reported in our previous studies, PFOS can be effectively removed by NF270 membrane [21] and novel poly (m-phenylene isophthalamide) hollow fiber nanofiltration membrane [22]. However, severe membrane fouling may become a crucial problem for the actual application of NF membranes on the PFOS removal. More efforts are worthwhile to be devoted to develop NF membrane and its combination technology for removing trace amount of PFOS from natural water.

Coagulation is commonly used as a pretreatment protocol to alleviate the membrane fouling. It has been reported that combining NF and coagulation treatment is able to effectively reduce membrane fouling as well as enhance the rejection of organic matters and ionic salts. Listiarini et al. [23] claimed that using hybrid coagulation-nanofiltration membrane (NF270 and NF90) systems can separate bromate and humic acid with mild fouling effect. Therefore, it might be expected that a hybrid coagulation-nanofil tration process would offer a more effective way to remove low concentrated PFCs from water.

Humic acid (HA) is abundant in natural water resources, and it has been recognized that hydrophobic organic contaminants are likely to interact with HA and precipitate from water. Deng et al. and Hansen et al. reported that some of the PFOS and perfluorooctanoic acid (PFOA) molecules in river water can be absorbed by sediments $[24,25]$. Hence, it is reasonable to expect that PFOS will attach to certain organic matters existing in the natural water, and this phenomenon will certainly affect the retention efficiency of NF membranes. In addition, the presence of HA can also result in membrane fouling, changes of surface charge, hydrophobicity, and solute rejection of NF membranes. Furthermore, fouling behavior is also highly dependent on the type of the membrane used [26]. Therefore, it is important to investigate the separation performances on the PFOS removal using different NF membranes under the effect of HA.

The main purpose of this study was to investigate the effect of coagulation pretreatment on the removal efficiency of PFOS and the water flux of two different commercial NF membranes (HYDRACORE and NF270). The effect of coagulant dosage on the PFOS removal efficiency was first investigated. Then the relations of the PFOS rejection and water flux versus NF process and filtration time were studied. At last, a series of characterizations such as HA and PFOS accumulation on the membranes, scanning electron microscopy (SEM) and surface $\zeta$ potential analysis were also carried out to understand the separation mechanism.

\section{Materials and methods}

\subsection{Materials}

Unless otherwise specified, all chemicals and reagents were analytical grade. The potassium salt form of PFOS (99\%) was supplied by AccuStandard Inc. (New Haven USA). HPLC-grade methanol, acetonitrile, isopropanol, sodium chloride, sodium bicarbonate, sodium hydroxide and hydrochloric acid were purchased from Fisher Scientific (Waltham, MA, USA). Aluminum chloride, as the coagulant, was provided by Beijing Chemical Company. Humic acid used in this study was purchased from Sigma-Aldrich (St. Louis, MO, USA). The stock solution was prepared by dissolving $2 \mathrm{~g}$ of HA into $1000 \mathrm{~mL}$ of DI water. The solution was filtered through a $0.45 \mu \mathrm{m}$ filter to remove particulates and stored at $4{ }^{\circ} \mathrm{C}$ before use.

NF experiments were performed using two different commercial flat-sheet NF membranes, HYDRACORE and NF270. The effective membrane area is $139 \mathrm{~cm}^{2}$ and the general characteristics of the two NF membranes are listed in Table 1.

\subsection{Coagulation experiment}

All the testing solutions contained $10 \mathrm{mM} \mathrm{NaCl}$ and $5 \mathrm{mM}$ $\mathrm{NaHCO}_{3}$. The concentration of PFOS in the solution was $100 \mu \mathrm{g} / \mathrm{L}$. The $\mathrm{pH}$ of the solution was adjusted to 7.5 by adding hydrochloric acid $(\mathrm{HCl})$ or sodium hydroxide $(\mathrm{NaOH})$. $\mathrm{HA}$ was added into some of the testing solutions to make the HA concentration at $20 \mathrm{mg} / \mathrm{L}$ to investigate the influence on PFOS removal. Different amount of $\mathrm{AlCl}_{3}$ were also added to some of the $1 \mathrm{~L}$ testing solution with the $\mathrm{AlCl}_{3}$ concentrations in the range of $0.1-1.0 \mathrm{mmol} / \mathrm{L}$ to conduct the coagulation experiment.

Standard jar tests were conducted to evaluate the coagulation efficiency. The solution was first stirred at $250 \mathrm{rpm}$ for $30 \mathrm{~s}$, and then was added with a predetermined amount of $\mathrm{AlCl}_{3}$ followed by mega-stirred at $200 \mathrm{rpm}$ for $1 \mathrm{~min}$. Afterwards, the mixing speed was reduced to $40 \mathrm{rpm}$ and kept for $15 \mathrm{~min}$ to allow the growth of floc. Finally, the stirring was stopped and the suspension was left undisturbed for $20 \mathrm{~min}$. After settling, the supernatant was filtered through a glass fiber filter (GFF, pore size $0.45 \mu \mathrm{m}$ ) to detect the HA concentration, while the PFOS concentration in the solution was measured after filtering it using a $0.22 \mu \mathrm{m}$ filter.

\subsection{Nanofiltration process}

The filtration experiments were conducted using a cross-flow laboratory-scale membrane test unit (CEPA CFII, GE Osmonics, USA) which consisted of a feed tank ( $5 \mathrm{~L})$, high-pressure pump (D03 Hydracell, Wanner Engineering, USA), pressure gauge and 
Table 1

General characteristics of the NF membranes.

\begin{tabular}{|c|c|c|c|c|c|}
\hline Membrane & Manufacturer & $\mathrm{MWCO}^{\mathrm{a}}$ & Water flux ${ }^{c}\left(\mathrm{~m}^{3} / \mathrm{s} \mathrm{m}^{2} \mathrm{kPa}\right)$ & $\mathrm{Mg}^{2+}$ rejection ${ }^{\mathrm{b}}(\%)$ & Surface charge $^{\mathrm{c}}(\mathrm{mV})$ \\
\hline HYDRACORE50 & Hydranautics & 1000 & $1.5 \times 10^{-3}$ & 60 & -52.3 \\
\hline NF270-400 & Dow & 200 & $3.1 \times 10^{-5}$ & 97 & -34.7 \\
\hline
\end{tabular}

a Molecular weight cut-off (MWCO) refers to the lowest molecular weight solute in which $90 \%$ of the solute is retained by the membrane.

b Information provide by manufacturer under the testing condition: $\left[\mathrm{MgSO}_{4}\right]=500 \mathrm{mg} / \mathrm{L} ; \mathrm{TMP}=0.55 \mathrm{MPa}$.

c Measured in this study.

membrane filtration cell (as shown in Fig. 1). Flat membrane coupons $(14.6 \times 9.5 \mathrm{~cm})$ were rinsed with DI water, soaked in a distilled water bath for $24 \mathrm{~h}$, and then pre-compacted for $48 \mathrm{~h}$ by filtering with DI water until a steady-state flux was obtained. Subsequently, certain amount of PFOS and salt solution were introduced into the feed tank, and then the NF experiment was started. A cross-flow rate of $1.5 \mathrm{~L} / \mathrm{min}$ was used for all tests. The feed temperature was controlled at $20 \pm 1{ }^{\circ} \mathrm{C}$ by a water bath. The permeate was collected in different time intervals for PFOS concentration determination and the changes of membrane permeate flux with time was monitored. In order to neutralize the effect of membrane properties on membrane fouling, normalized permeate flux was used in this study according to the following equation [27]:

$$
\begin{aligned}
& \text { Normalized permeate flux }\left(J / J_{0}\right) \\
& =\frac{\text { Measured permeate flux }(J)}{\text { Pure water flux }\left(J_{0}\right)}
\end{aligned}
$$

where the measured permeate flux $\left(\mathrm{L} / \mathrm{m}^{2} \mathrm{~h}\right)$ was tested in the different time intervals during the experiments, and pure water flux $\left(\mathrm{L} / \mathrm{m}^{2} \mathrm{~h}\right)$ was tested using DI water.

The effect of organic matter and coagulation pretreatment on the permeate flux and PFOS rejection as a function of transmembrane pressure and filtration time was studied for each NF membrane. Three different solutions, DI water, HA solution and the permeate water from the coagulation process, were investigated in the NF processes to study the effects of HA and coagulation pretreatment on the PFOS rejection of the NF membranes. $\mathrm{NF}$ experiments were carried out according to the total recycle configuration in which both permeate and retentate streams were recycled to the feed tank. Four different trans-membrane pressures (TMP), i.e. $0.4,0.8,1.0$ and $1.2 \mathrm{MPa}$, were applied in the filtration experiments. The suspensions after the coagulation processes were analyzed to determine the amount of PFOS precipitated. In the coa gulation-nanofiltration process, PFOS was first coagulated in a $0.60 \mathrm{mmol} / \mathrm{L} \mathrm{AlCl}_{3}$ solution and then filtered. The permeate solution was used for the NF experiments.

\subsection{Sample analysis}

The PFOS concentrations in the feed and permeate samples were measured by ultra-performance liquid chromatography-tandem mass spectrometry (UPLC/MS/MS) with a UPLC system (Waters Corp., USA) equipped with a C18 column (BEH, particle size $1.7 \mu \mathrm{m}, 2.1 \times 100 \mathrm{~mm}$ i.d., Waters Corp., USA) and an MS system Quattro Premier XE tandem quadrupole mass spectrometer (Waters Corp., USA) with an electrospray ionization source. The mobile phase was a binary mixture of solvent A $(10 \mathrm{mmol} / \mathrm{L}$ ammonium acetate in MilliQ water) and B (100\% acetonitrile) applied at a flow rate of $0.2 \mathrm{~mL} / \mathrm{min}$. The ratio of the two solvents was $30 \% \mathrm{~A}$ to $70 \% \mathrm{~B}$ and the injection volume was $10 \mu \mathrm{L}$. The tandem MS analysis was conducted using the multiple reaction monitoring (MRM) mode with a cone voltage and collision energy of $30 \mathrm{~V}$ and $11 \mathrm{~V}$, respectively.

At each condition, at least three experiments were carried out and the results were found to vary within $\pm 5 \%$. The rejection of PFOS was calculated according to Eq. (2):

$R(\%)=\left(1-\frac{C_{p}}{C_{f}}\right) \times 100$

where $R$ is the rejection (\%), $C_{f}$ and $C_{p}$ are the solute concentrations in the feed and permeate $(\mu \mathrm{g} / \mathrm{L})$, respectively.

The concentration of HA was determined by UV spectrophotometer (HACH Corp. USA). A fine linear relationship between $\mathrm{UV}_{254}$ absorbance and the concentration of HA was observed.

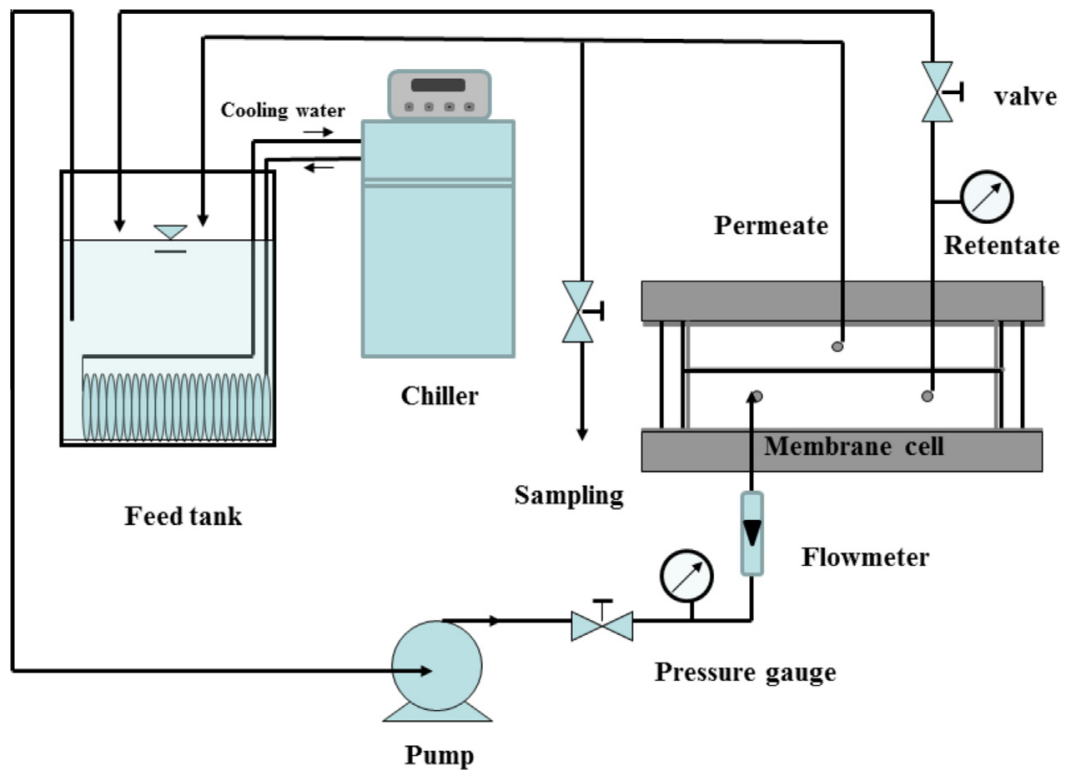

Fig. 1. Cross-flow laboratory-scale membrane test unit used in this study. 


\subsection{Measurement of PFOS accumulation on membrane}

To measure the amount of PFOS adsorbed on the membrane surface after the NF experiment, we adopted the method proposed by Tang et al. [17]. Specifically, each fouled HYDRACORE membrane sample was soaked in a $50 \%$ (by volume) isopropanol/water solution in a beaker which was placed in a shaker overnight to desorb PFOS completely. The concentration of PFOS in the solution was measured using HPLC/MS/MS.

\subsection{XPS analysis}

The XPS spectra were acquired on PHI Quantera SXM Scanning $\mathrm{X}$-ray microprobe. The operating pressure was $4.5 \times 10^{-12}$ Bar with Al Ka X-ray anode radiation source was used as the excitation source $(h v=1486.7 \mathrm{eV})$. Curve fittings of $C 1 \mathrm{~s}$ spectra were using XPS Peak software to analysis. All XPS spectra were referenced with $C 1 \mathrm{~s}$ binding energy at $284.8 \mathrm{eV}$. The XPS spectra were using Shirley-type background to subtract, the Gaussian-Lorentzian peak shape were used after performing background.

\subsection{Zeta potential measurement}

Zetasizer Nano ZS 90 series (Malvern, UK) were used to obtain the zeta potential of membranes surface. The concentration at $0.01 \mathrm{~mol} / \mathrm{L} \mathrm{NaCl}$ solution with ultrapure water and adjusted $\mathrm{pH}=7$ used for each membrane during the experiment. In this process, a given electric field is applied across the membrane. The weak binding ions of the double layer will be moved in the electric field. Zeta potentials were calculated from the measured electroosmosis potentials using Smoluchowski equation [28]:

$$
\zeta=\frac{\mu \cdot K \cdot L}{\varepsilon_{r} \cdot \varepsilon_{0} \cdot E_{z}^{2} \cdot A\left(\lambda_{b 2}-\lambda_{b 1}\right)}
$$

where $\varepsilon_{r}$ and $\varepsilon_{0}$ are the relative dielectric constant, $\mu$ is the solution viscosity, $L$ is the length of the channel, $K$ is the slope that change in current and time over the linear range, $E_{z}$ is the applied electric field strength, $A$ is the area of the channel, $\lambda_{b 2}-\lambda_{b 1}$ is the difference in channel conductivity between the high and low concentration solution.

\subsection{SEM analysis}

The surface morphologies of both the virgin and fouled membranes were monitored by a Hitachi S4500 Field Emission Scanning Electron Microscope (FESEM) at an acceleration voltage of $15 \mathrm{kV}$.

\subsection{AFM analysis}

A Multimode SPM equipped with a J-type piezoelectric scanner and a Nanoscope III a controller (Digital Instruments, USA) was used to measure the AFM. The membrane surface images were obtained with a scan size of $5 \mu \mathrm{m} \times 5 \mu \mathrm{m}$.

\section{Results and discussion}

\subsection{Effect of $\mathrm{AlCl}_{3}$ dose on the removal of PFOS and HA during} coagulation process

The effect of $\mathrm{AlCl}_{3}$ dosage on the removal of $20 \mathrm{mg} / \mathrm{L} \mathrm{HA}$ and $100 \mu \mathrm{g} / \mathrm{L}$ PFOS during single coagulation process was studied and the results are shown in Fig. 2 a.
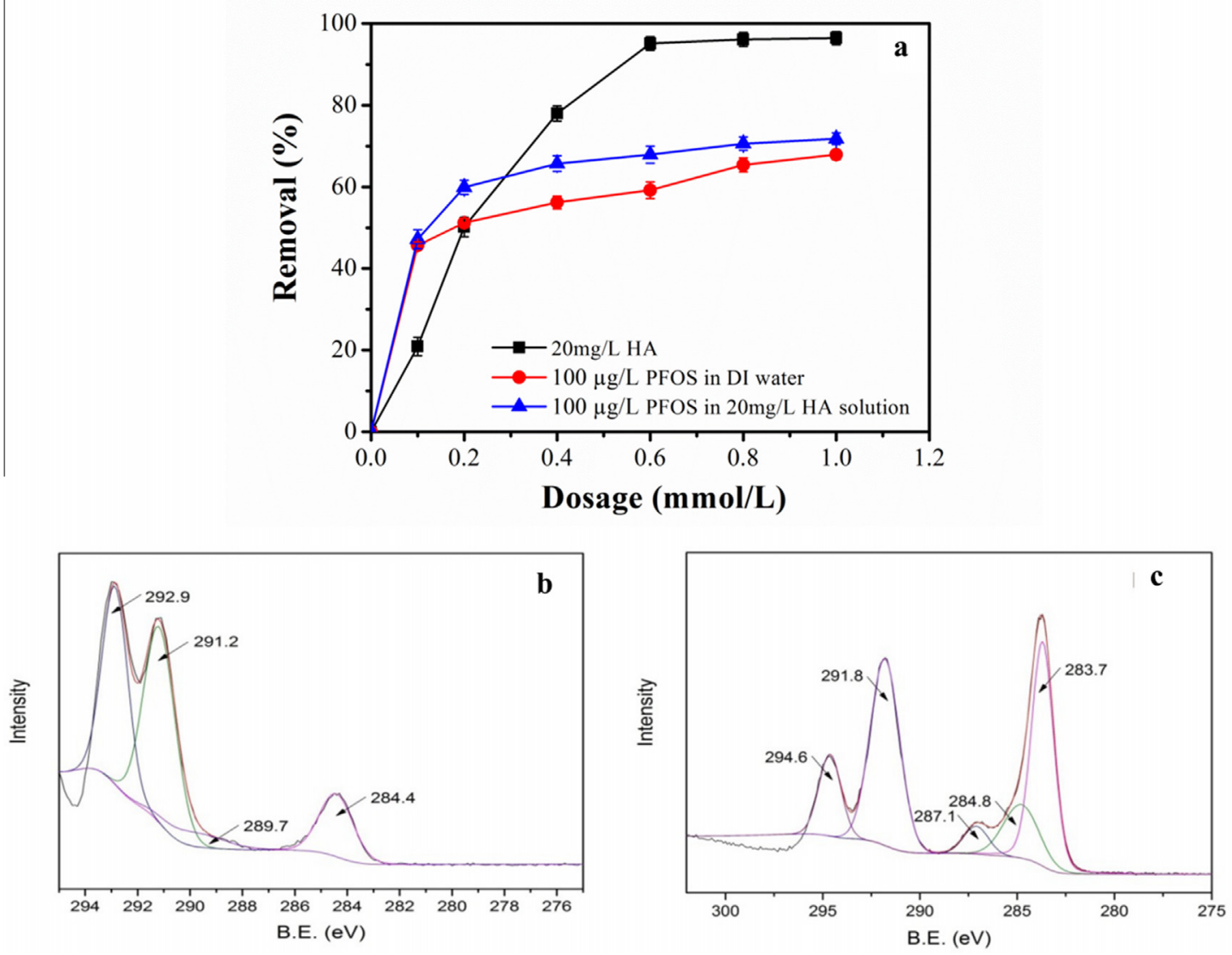

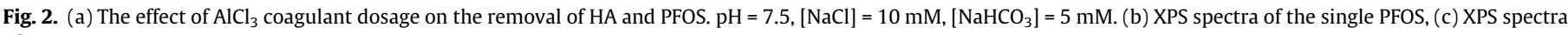
of PFOS + HA. 

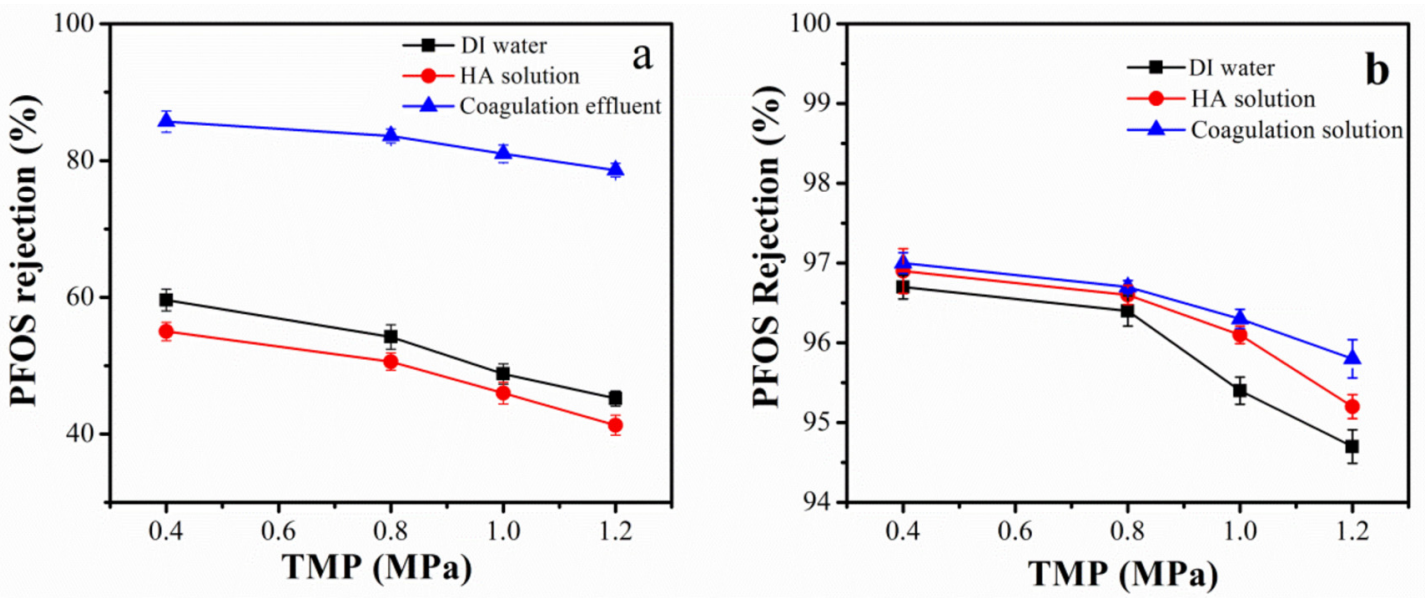

Fig. 3. The effect of trans-membrane pressure on the PFOS rejections: (a) HYDRA-CORE, and (b) $\mathrm{NF} 270 \mathrm{membrane} . \mathrm{pH}=7.5, \mathrm{cross}-\mathrm{flow}$ rate $=1.5 \mathrm{~L} / \mathrm{min}, T=20 \pm 1{ }^{\circ} \mathrm{C}$.

The removal efficiencies of both HA and PFOS are enhanced with increasing the $\mathrm{AlCl}_{3}$ dosage from 0 to $0.60 \mathrm{mmol} / \mathrm{L}$, and then become relatively stable at the higher $\mathrm{AlCl}_{3}$ concentrations. When the $\mathrm{AlCl}_{3}$ concentration reaches $0.60 \mathrm{mmol} / \mathrm{L}$, the removal efficiencies of HA and PFOS are $95.1 \%$ and $60.0 \%$, respectively. It is well known that HA, as complex macromolecules with abundant functional groups such as carboxylic and phenolic acids, at typical $\mathrm{pH}$ conditions will have a net negative charge [29]. Various studies have also reported that the coagulation can effectively remove HA from water [30-32]. As reported, PFOS is easily attached to hydrolysis products formed in the coagulation process due to its hydrophobic character [25]. Also, the zeta potential of hydrolyzed $\mathrm{Al}$ (III) species remains negative in the whole range of coagulant dosage (from 0.1 to $1.0 \mathrm{mmol} / \mathrm{L}$ ) [33] and PFOS exists as anions in water according to its $p K_{a}$ value [34], the negative charged PFOS ions tend to stick to a polymer containing positive charged aluminum hydrolysate or floc via electrostatic attraction, and then precipitate from water.

It is observed that the removal efficiency of PFOS is enhanced by adding HA in the solution. The main reason for this may be due to adsorption of PFOS on the HA molecules. After the adsorption, PFOS can be removed together with HA during the coagulation. A similar result was found by Higgins et al. [35] who reported that the PFOS adsorption on organic matters in the sediments of natural water occurred via hydrophobic partition. XPS analysis was conducted

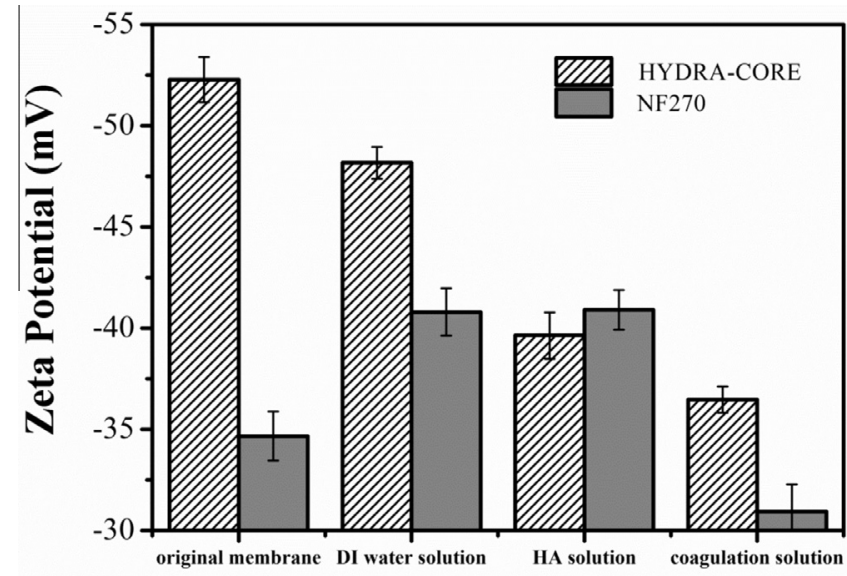

Fig. 4. $\zeta$ surface potential of the virgin and fouled membranes in different solutions. $\mathrm{pH}=7,[\mathrm{NaCl}]=0.01 \mathrm{~mol} / \mathrm{L}$. to further investigate the interaction between PFOS and HA and the high-resolution $C 1 \mathrm{~s}$ XPS spectra are also shown in Fig. 2. Comparing to single PFOS substance (Fig. 2b), it can be seen that HA (Fig. 2c) can chemically bond with PFOS, $\mathrm{CF}_{2}$ bonds have positively shifted from $291.2 \mathrm{eV}$ to $291.8 \mathrm{eV}$ which means the functional groups of HA have decrease the electron cloud density of CF groups [36]. Because the chemical structure of PFOS is well known, two new peaks at $284.8 \mathrm{eV}$ and $287.1 \mathrm{eV}$ respectively assigned to $\mathrm{C}-\mathrm{O}$ and $\mathrm{N}-\mathrm{C}-\mathrm{O}$ bonds [37], should come from HA functional groups. Another new peak at $294.6 \mathrm{eV}$ was reported but not explained by any other researchers.

According to above results, it can be found that coagulation can remove most PFOS from water, but the residual PFOS concentration in water is still high. That is to say, the conventional coagulation is not sufficient to remove PFOS. In this case, we add nanofiltration membrane process after coagulation process to investigate PFOS removal.

\subsection{PFOS removal by nanofiltration process}

Fig. 3 shows that the PFOS rejections of the NF270 membrane exceed $94 \%$ for all three solutions, while the rejections of the HYDRACORE membrane are between $40 \%$ and $85 \%$ in the same experimental conditions. The higher PFOS rejections of the NF270 membrane than those of the HYDRACORE membrane are because of the smaller pore sizes of the former. Note that, the molecular weight cut-off (MWCO) of the NF270 and HYDRACORE membranes are $200 \mathrm{~g} / \mathrm{mol}$ and $1000 \mathrm{~g} / \mathrm{mol}$, respectively. Since the molecular weight of PFOS is $500 \mathrm{~g} / \mathrm{mol}$, it is the reason of the lower rejection to PFOS of the HYDRACORE membrane. Fig. 3 also shows that the PFOS rejection decreases with the increase of operating pressure

Table 2

Comparison of the removal efficiency of PFOS by different NF membrane systems.

\begin{tabular}{llll}
\hline System & $\begin{array}{l}\text { PFOS conc. } \\
(\mathrm{mg} / \mathrm{L})\end{array}$ & $\begin{array}{l}\text { Removal efficiency } \\
(\%)\end{array}$ & Refs. \\
\hline DK $^{\mathrm{a}}$ & 10 & $\sim 97$ & {$[17]$} \\
XLE $^{\mathrm{b}}$ & 0.002 & $\sim 99$ & {$[34]$} \\
$\mathrm{NF90}$ & 10 & $\sim 99$ & {$[17]$} \\
$\mathrm{NF270}$ & 10 & $\sim 90$ & {$[17]$} \\
NF270 & $0.01-0.5$ & $\sim 94$ & {$[35]$} \\
NF270 & 0.003 & $\sim 99$ & {$[34]$} \\
Coagulation & 0.2 & $\sim 86$ (HYDRACORE) & This \\
$\quad+$ nanofiltration & & $\sim 97$ (NF270) & study
\end{tabular}

a Manufacturer: GE; MWCO: 150-300; permeate flux: $3.9 \times 10^{-6} \mathrm{~m}^{3} / \mathrm{s} \mathrm{m}^{2} \mathrm{kPa}$.

b Manufacturer: dow; MWCO: 100; permeate flux: $1.7 \times 10^{-5} \mathrm{~m}^{3} / \mathrm{s} \mathrm{m}^{2} \mathrm{kPa}$. 
for both NF270 and HYDRACORE membranes. This may be due to the interaction between organic matter and the membrane surface. It is consistent with Nghiem et al. result that an increase in transmembrane pressure may lead to a decrease in steroid hormone retention for NF membranes [38].

Fig. 3 also shows that the rejection to PFOS in the HA solution is lower than that in DI water for the HYDRACORE membrane, whereas an opposite trend is observed for the NF270 membrane. These results may be caused by the differences in the $\zeta$ surface potential between the two membranes. The $\zeta$ surface potential has been used to explore the relationship between membrane properties and membrane rejection [39]. When separating ionic species, the rejection mechanism of NF membrane includes both size exclusion and electrostatic repulsion. Therefore, membrane surface charge plays an important role in transport process of the charged solute through a NF membrane.

As shown in Fig. 4, the virgin HYDRACORE membrane has a stronger negative charge than that of the NF270 membrane $(-52.3$ and $-34.7 \mathrm{mV})$. The $\zeta$ surface potential of the HYDRACORE membrane decreases to $-48.2 \mathrm{mV}$, whereas that of the NF270 membrane increases to $-40.8 \mathrm{mV}$ after filtering the PFOS in DI water solution. Such changes in the $\zeta$ surface potential of the membranes are probably caused by the adsorption of PFOS onto the membrane surfaces [17]. As we known, PFOS, as a strong acid with $p K_{a}$ of around -3 , is composed of an eight-carbon perfluorinated alkane and a sulfonate group $\left(\mathrm{CF}_{3}\left(\mathrm{CF}_{2}\right)_{7} \mathrm{SO}_{3} \mathrm{H}\right)$ [40]. This means that
PFOS would exist in the form of anion $\left(\mathrm{CF}_{3}\left(\mathrm{CF}_{2}\right)_{7} \mathrm{SO}_{3}^{-}\right)$at $\mathrm{pH}>3$. As shown in Table 3, it can be seen that the accumulation of PFOS on the HYDRACORE membrane is more than that on the NF270 membrane. Therefore, the shift trend of the $\zeta$ surface potential after the PFOS adsorption would be more dependent on the electronic property of the sulfonate group, which may be the reason that opposite surface potential change was observed for the two NF membranes. It is observed that the $\zeta$ surface potential of the HYDRACORE membranes further decreases after filtering the PFOS in a $20 \mathrm{mg} / \mathrm{L} \mathrm{HA}$ solution. In consideration of the membrane MWCO and the molecular weight of PFOS, electrostatic repulsion may play a dominant role when separating PFOS using the HYDRACORE membrane. The decreased $\zeta$ surface potential of HYDRACORE membrane results in a lower rejection to PFOS in HA solution than in DI water. Cho et al. have observed that NOMs fouling resulted in a reduction in negative charge and an increase in the hydrophobicity of the membrane surface [41]. Bellona et al. reported that the properties and rejection characteristics of three NF membranes (NF270, TFC-S and NF90) could be influenced by the secondary-treated wastewater effluent [42]. Membrane fouling resulted in an increase in hydrophobicity and a decrease in surface charge for the TFC-S and NF270 membranes, but a decrease in hydrophobicity and an increase in surface charge for the NF90 membrane. Note that, there is no significant change in the $\zeta$ surface potential of the NF270 membrane after filtering the PFOS in either HA solution or DI water. In this study, the NF270 membrane is considered as a tight
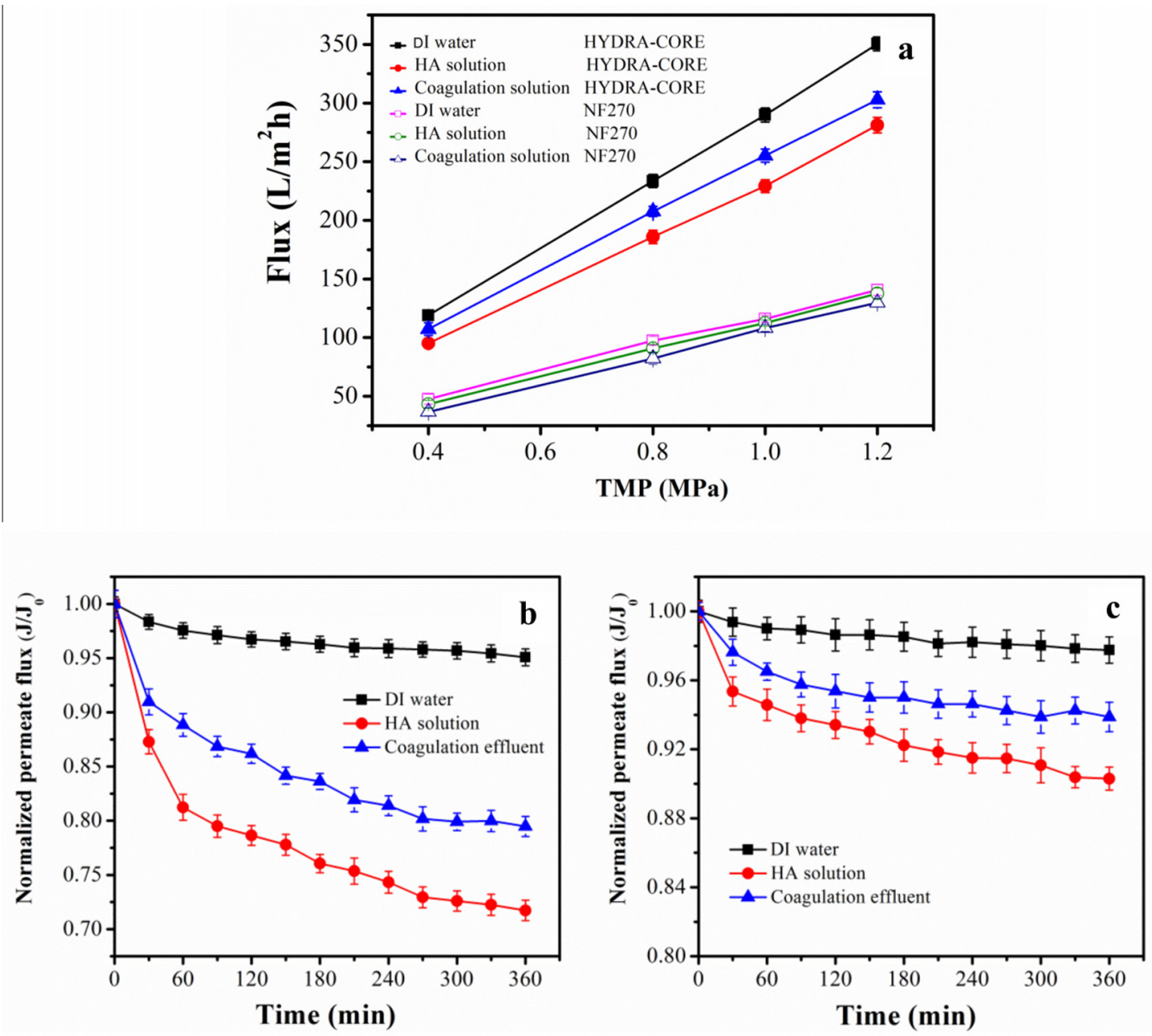

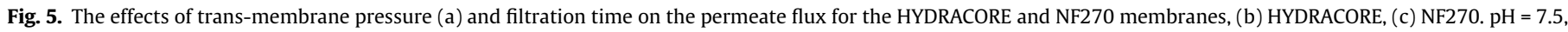
cross-flow rate $=1.5 \mathrm{~L} / \mathrm{min}, T=20 \pm 1{ }^{\circ} \mathrm{C}$. 

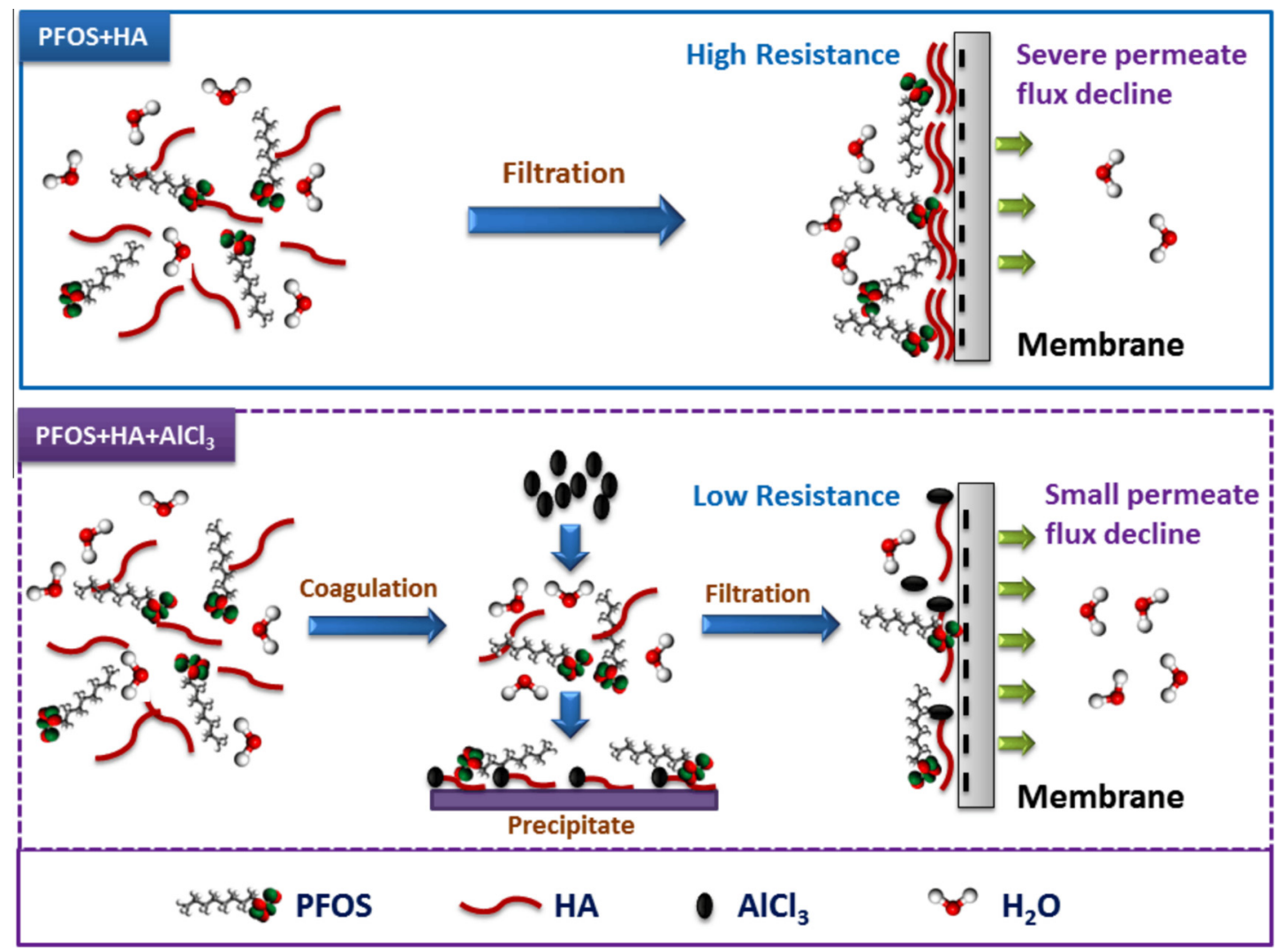

Fig. 6. Schematic of membrane fouling formation for the PFOS system.

Table 3

Accumulation of HA and PFOS on the membrane surface in the different solutions.

\begin{tabular}{llllll}
\hline \multirow{2}{*}{ System } & HYDRACORE & & & NF270 \\
\cline { 2 - 3 } \cline { 5 - 6 } \cline { 5 - 6 } & $\mathrm{HA}\left(\mu \mathrm{g} / \mathrm{cm}^{2}\right)$ & PFOS $\left(\mathrm{ng} / \mathrm{cm}^{2}\right)$ & & $\begin{array}{l}\mathrm{HA} \\
\left(\mu \mathrm{g} / \mathrm{cm}^{2}\right)\end{array}$ & $\begin{array}{l}\text { PFOS } \\
\left(\mathrm{ng} / \mathrm{cm}^{2}\right)\end{array}$ \\
\hline DI water & - & 155.0 & - & 91.9 \\
HA solution & 28.3 & 161.3 & 18.8 & 135.6 \\
Coagulation effluent & 12.6 & 137.4 & & 10.5 & 78.2 \\
\hline
\end{tabular}

NF membrane compared with the HYDRACORE membrane. And the separation process in NF 270 is mainly controlled by size exclusion. Pore blocking caused by HA adsorption on the membrane surface may improve PFOS rejection of the NF270 membrane, which is consistent with the results reported by Nghiem et al. [43]. On the other hand, the HA fouling layer on the membrane surface might act as a secondary membrane and improve solute rejection.

It is worthwhile to note that the combination of coagulation and nanofiltration enhances the removal efficiency of PFOS for both NF membranes, especially for HYDRACORE membrane of which the PFOS rejections increases from 55\% to $86 \%$ at a trans-membrane pressure of 0.4 MPa. This shows that the coagulation pretreatment can significantly enhance the rejection efficiency of the loose membrane. A comparison of the removal efficiency of PFOS by different NF membrane systems is shown in Table 2. It is worthwhile to note that PFOS can be effectively removed by both tight (NF270) and loose (HYDROCORE) NF membranes in the mode of hybrid coagulation and nanofiltration process. In addition, studies have reported that coagulation can effectively remove the high concentration of PFOS from water $[25,44]$. Thus, coagulation can also be used for treating the retentate stream from the NF system in which PFOS is highly concentrated.
Fig. 5a shows that the water fluxes linearly increase with the increase in TMP. This is in accordance with previous studies [45-47]. As shown in Fig. 5b and c, the fluxes of both NF membranes in the three solutions gradually decrease during experiments. Comparing to Fig. $5 \mathrm{~b}$ and $\mathrm{c}$, it can be seen that the HYDRACORE membrane exhibits a greater flux reduction than the NF270 membrane in all three cases. This observation is similar with the result reported by Tang et al. who also claims that the more permeable membranes generally shows a more severe flux decrease [17]. The most severe decline in flux is happened in the HA solution for both NF membranes. As reported in previous studies, the fouling layer that was formed by HA depositing on the membrane surface increased the permeate resistance [48]. It is noticed that coagulation pretreatment can greatly improve the permeate flux in the NF process. From a schematic diagram (Fig. 6), it can be seen that HA can be effectively removed in the coagulation process and forms the flocs in the coagulation permeate [49], resulting in a loosely packed fouling layer on the NF membrane surface.

\subsection{Membrane fouling analysis}

To explore the rejection mechanism of PFOS by NF membranes, the accumulations of HA and PFOS in membranes were individually measured using UV spectrophotometer and LC/MS/MS. The accumulation amount in per unit membrane area is calculated and the data is shown in Table 3. The maximum accumulations of HA and PFOS of both NF membranes are observed when separating PFOS in the HA solutions. The interaction between the HA and PFOS is the reason that enhances the accumulation of PFOS during the filtration process. As HA forms a fouling layer on the membrane surface, the rejection of PFOS can be increased. The minimum accumulations of $\mathrm{HA}$ and PFOS are observed in the coagulation-NF 

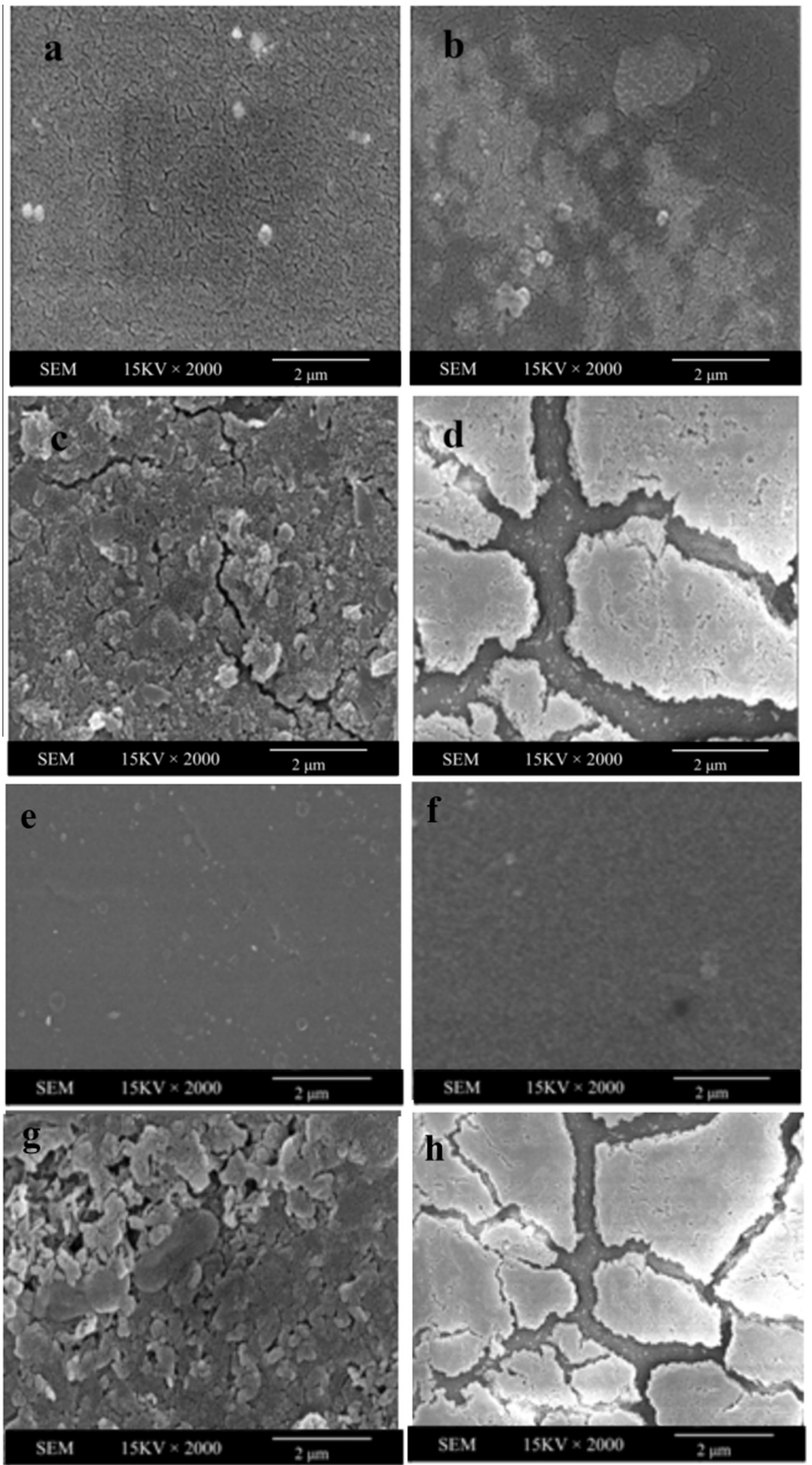

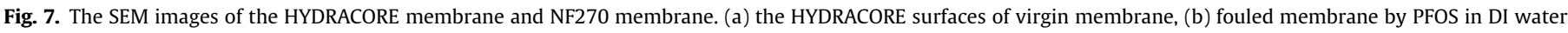

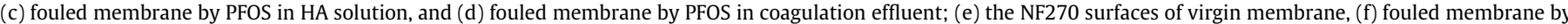
PFOS in DI water, $(\mathrm{g})$ fouled membrane by PFOS in HA solution, and $(\mathrm{h})$ fouled membrane by PFOS in coagulation effluent. 
a

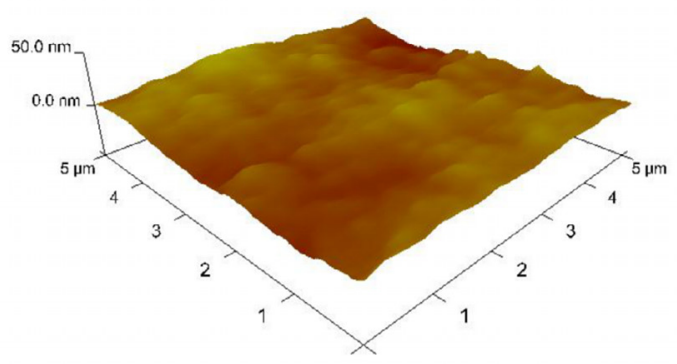

c

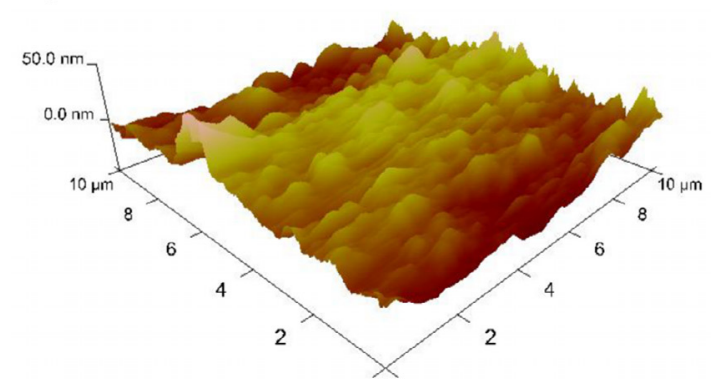

b

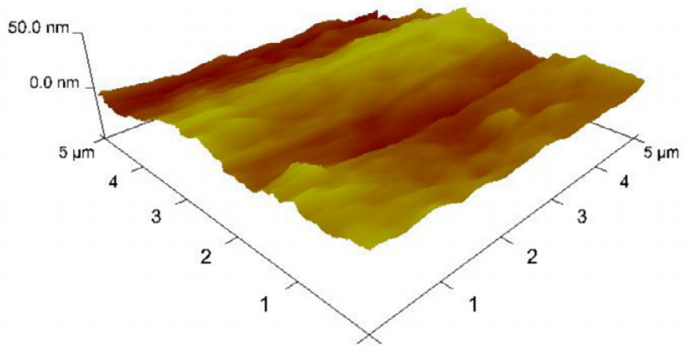

d

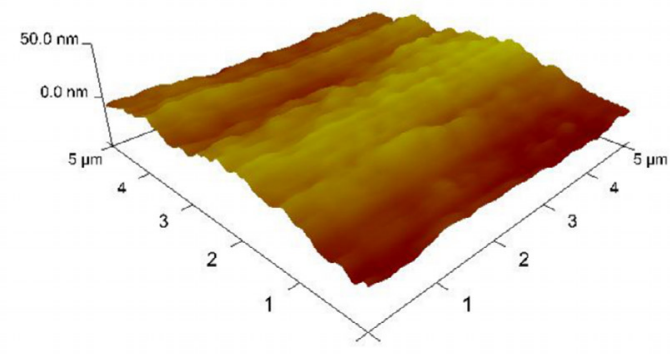

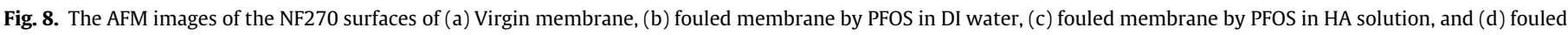
membrane by PFOS in coagulation effluent.

processes for both NF membranes. This may be explained by the reason that most PFOS has been removed during the coagulation pretreatment process. The concentration of PFOS in the influent of the NF membranes should also be much lower than other conditions. In addition, there is the adsorption between the flocs and NF membrane surface via electrostatic interaction and the adsorption sites on the membrane surface are limited, the accumulation of PFOS on the membrane surface in the coagulation-NF process is the lowest. The more HA accumulation for the HYDRACORE membrane is corresponding to the more flux reduction observed in the NF filtration process.

Based on the result in Table 3, more severe fouling of HA and PFOS form on the surface of membrane. The SEM analysis was conducted on the fouled HYDRACORE membranes to investigate the effect of HA and coagulation pretreatment on the NF membrane filtration process.

Comparing to virgin HYDRACORE membrane (Fig. 7a) and NF270 membrane (Fig. 7e), there are no obvious fouling layer observed on the NF membrane surface after filtering the PFOS in DI water of HYDRACORE membrane (Fig. 7b) and NF270 membrane (Fig. 7f). A thick and dense fouling layer are formed on the membrane surface after filtering the PFOS in HA solution for HYDRACORE membrane (Fig. 7c) and NF270 membrane (Fig. 7g). HYDRACORE membrane (Fig. 7d) and NF270 membrane (Fig. 7h) show a permeable loosely packed fouling layer after filtering the coagulation solution. In addition, obvious cracks can be observed on the fouling layer. The SEM samples were required to dry in the air before the measurement. The occurrence of the cracks indicates that water content in the fouling layer formed by flocs should be much higher than that formed by HA. This also means that the bulk solution would be easier to pass through the flocs formed layers.

Also we investigate the AFM image of NF270 membrane, and corresponding images is shown in Fig. 8.

It can also be seen that there is no obvious roughness changes on the NF270 membrane surface after filtering the PFOS in DI water (Fig. 8b) than virgin membrane (Fig. 8a). After filtering the PFOS in HA solution a more roughness is observed on the mem- brane surface (Fig. 8c) than that in Fig. 8d after filtering the coagulation solution. The results are consistent with the water flux observed from the NF process. Listiarini et al. also observed that the fouling layers formed by the large and loose flocs resulted in a low filtration resistance on the membrane surface [27].

\section{Conclusions}

PFOS species were effectively removed by coagulation-nanofil tration process. The presence of HA can enhance the removal efficiency of PFOS. The NF270 membrane showed a higher PFOS rejection than the HYDRACORE membrane at the same operating condition. The $\zeta$ surface potential of both NF membranes decreased the most after filtering the coagulation permeate water due to the accumulation of flocs. The coagulation pretreatment can significantly enhance the permeate flux and form a more permeable fouling layer. A thick and dense fouling layer was formed on the membrane surface when filtering PFOS in HA solution and the maximum accumulation of PFOS was observed in the HA solution for both NF membranes.

\section{Acknowledgements}

The financial support provided by the National Natural Science Foundation of China (No. 21476248 and 21176245), the National Science and Technology Support Program of China (Grant no. 2012BAJ25B02 and 2012BAJ25B06), and Youth Innovation Promotion Association CAS are gratefully acknowledged by the authors.

\section{References}

[1] J.W. Martin, K. Kannan, U. Berger, P.D. Voogt, J. Field, J. Franklin, J.P. Giesy, T. Harner, D.C.G. Muir, B. Scott, M. Kaiser, U. Järnberg, K.C. Jones, S.A. Mabury, H. Schroeder, M. Simcik, C. Sottani, B.V. Bavel, A. Kärrman, G. Lindström, S.V. Leeuwen, Peer reviewed: analytical challenges hamper perfluoroalkyl research, Environ. Sci. Technol. 38 (2004) 248A-255A.

[2] B.D. Key, R.D. Howell, C.S. Criddle, Defluorination of organofluorine sulfur compounds by Pseudomonas sp. strain D2, Environ. Sci. Technol. 32 (1998) 2283-2287. 
[3] J.P. Giesy, K. Kannan, Global distribution of perfluorooctane sulfonate in wildlife, Environ. Sci. Technol. 35 (2001) 1339-1342.

[4] J.L. Newsted, P.D. Jones, K. Coady, J.P. Giesy, Avian toxicity reference values for perfluorooctane sulfonate, Environ. Sci. Technol. 39 (2005) 9357-9362.

[5] D.J. Luebker, K.J. Hansen, N.M. Bass, J.L. Butenhoff, A.M. Seacat, Interactions of flurochemicals with rat liver fatty acid-binding protein, Toxicology 176 (2002) $175-185$.

[6] W. Hu, P.D. Jones, B.L. Upham, J.E. Trosko, C. Lau, J.P. Giesy, Inhibition of gap junctional intercellular communication by perfluorinated compounds in rat liver and dolphin kidney epithelial cell lines in vitro and Sprague-Dawley rats in vivo, Toxicol. Sci. 68 (2002) 429-436.

[7] M. So, S. Taniyasu, N. Yamashita, J. Giesy, J. Zheng, Z. Fang, S. Im, P.K. Lam, Perfluorinated compounds in coastal waters of Hong Kong, South China, and Korea, Environ. Sci. Technol. 38 (2004) 4056-4063.

[8] M.K. So, Y. Miyake, W.Y. Yeung, Y.M. Ho, S. Taniyasu, P. Rostkowski, N. Yamashita, B.S. Zhou, X.J. Shi, J.X. Wang, J.P. Giesy, H. Yu, P.K.S. Lam, Perfluorinated compounds in the Pearl river and Yangtze river of China, Chemosphere 68 (2007) 2085-2095.

[9] N. Yamashita, K. Kannan, S. Taniyasu, Y. Horii, G. Petrick, T. Gamo, A global survey of perfluorinated acids in oceans, Mar. Pollut. Bull. 51 (2005) 658-668.

[10] M.K. So, S. Taniyasu, N. Yamashita, J.P. Giesy, J. Zheng, Z. Fang, S.H. Im, P.K.S. Lam, Perfluorinated compounds in coastal waters of Hong Kong, South China, and Korea, Environ. Sci. Technol. 38 (2004) 4056-4063.

[11] J. Hu, J. Yu, S. Tanaka, S. Fujii, Perfluorooctane sulfonate (PFOS) and perfluorooctanoic acid (PFOA) in water environment of Singapore, Water Air Soil Pollut. 216 (2011) 179-191.

[12] H. Chen, C. Zhang, J. Han, Y. Yu, P. Zhang, PFOS and PFOA in influents, effluents, and biosolids of Chinese wastewater treatment plants and effluent-receiving marine environments, Environ. Pollut. 170 (2012) 26-31.

[13] J. Yu, J. Hu, S. Tanaka, S. Fujii, Perfluorooctane sulfonate (PFOS) and perfluorooctanoic acid (PFOA) in sewage treatment plants, Water Res. 43 (2009) 2399-2408.

[14] B.G. Loganathan, K.S. Sajwan, E. Sinclair, K. Senthil, K. Senthil Kumar, K. Kannan, Perfluoroalkyl sulfonates and perfluorocarboxylates in two wastewater treatment facilities in Kentucky and Georgia, Water Res. 41 (2007) 4611-4620.

[15] M.M. Schultz, D.F. Barofsky, J.A. Field, Quantitative determination of fluorotelomer sulfonates in groundwater by LC MS/MS, Environ. Sci. Technol. 38 (2004) 1828-1835.

[16] C.Y.Y. Tang, Q.S. Fu, A.P. Robertson, C.S. Criddle, J.O. Leckie, Use of reverse osmosis membranes to remove perfluorooctane sulfonate (PFOS) from semiconductor wastewater, Environ. Sci. Technol. 40 (2006) 7343-7349.

[17] C.Y. Tang, Q.S. Fu, C.S. Criddle, J.O. Leckie, Effect of flux (transmembrane pressure) and membrane properties on fouling and rejection of reverse osmosis and nanofiltration membranes treating perfluorooctane sulfonate containing wastewater, Environ. Sci. Technol. 41 (2007) 2008-2014.

[18] F.J. Benitez, J.L. Acero, F.J. Real, C. Garcia, Removal of phenyl-urea herbicides in ultrapure water by ultrafiltration and nanofiltration processes, Water Res. 43 (2009) 267-276.

[19] A.R.D. Verliefde, S.G. Heijman, E.R. Cornelissen, G. Amy, B. Van der Bruggen, J.C. van Dijk, Influence of electrostatic interactions on the rejection with NF and assessment of the removal efficiency during NF/GAC treatment of pharmaceutically active compounds in surface water, Water Res. 41 (2007) 3227-3240.

[20] W.H. Pang, N.Y. Gao, S.J. Xia, Removal of DDT in drinking water using nanofiltration process, Desalination 250 (2010) 553-556.

[21] C. Zhao, J. Zhang, G. He, T. Wang, D. Hou, Z. Luan, Perfluorooctane sulfonate removal by nanofiltration membrane the role of calcium ions, Chem. Eng. J. 233 (2013) 224-232.

[22] T. Wang, C. Zhao, P. Li, Y. Li, J. Wang, Fabrication of novel poly(m-phenylene isophthalamide) hollow fiber nanofiltration membrane for effective removal of trace amount perfluorooctane sulfonate from water, J. Membr. Sci. 477 (2015) 74-85.

[23] K. Listiarini, J.T. Tor, D.D. Sun, J.O. Leckie, Hybrid coagulation-nanofiltration membrane for removal of bromate and humic acid in water, J. Membr. Sci. 365 (2010) 154-159.

[24] K.J. Hansen, H.O. Johnson, J.S. Eldridge, J.L. Butenhoff, L.A. Dick, Quantitative characterization of trace levels of PFOS and PFOA in the Tennessee river, Environ. Sci. Technol. 36 (2002) 1681-1685.

[25] S. Deng, Q. Zhou, G. Yu, J. Huang, Q. Fan, Removal of perfluorooctanoate from surface water by polyaluminium chloride coagulation, Water Res. 45 (2011) 1774-1780.
[26] M.A. Zazouli, H. Susanto, S. Nasseri, M. Ulbricht, Influences of solution chemistry and polymeric natural organic matter on the removal of aquatic pharmaceutical residuals by nanofiltration, Water Res. 43 (2009) 3270-3280.

[27] K. Listiarini, W. Chun, D.D. Sun, J.O. Leckie, Fouling mechanism and resistance analyses of systems containing sodium alginate, calcium, alum and their combination in dead-end fouling of nanofiltration membranes, J. Membr. Sci. 344 (2009) 244-251.

[28] A. Sze, D. Erickson, L. Ren, D. Li, Zeta-potential measurement using the Smoluchowski equation and the slope of the current-time relationship in electroosmotic flow, J. Colloid Interface Sci. 261 (2003) 402-410.

[29] B. Eikebrokk, Removal of humic substances by coagulation, in: H. Hahn, E. Hoffmann, H. Ødegaard (Eds.), Chemical Water and Wastewater Treatment IV, Springer, Berlin Heidelberg, 1996, pp. 173-187.

[30] X. Lu, Z. Chen, X. Yang, Spectroscopic study of aluminium speciation in removing humic substances by Al coagulation, Water Res. 33 (1999) 32713280.

[31] J. Duan, J. Wang, N. Graham, F. Wilson, Coagulation of humic acid by aluminium sulphate in saline water conditions, Desalination 150 (2002) 1-14.

[32] B. Shi, O. Wei, D. Wang, Z. Zhu, H. Tang, Coagulation of humic acid: the performance of preformed and non-preformed Al species, Colloids Surf. A 296 (2007) 141-148.

[33] C. Hu, H. Liu, J. Qu, D. Wang, J. Ru, Coagulation behavior of aluminum salts in eutrophic water: significance of Al13 species and pH control, Environ. Sci. Technol. 40 (2006) 325-331.

[34] Q. Yu, R. Zhang, S. Deng, J. Huang, G. Yu, Sorption of perfluorooctane sulfonate and perfluorooctanoate on activated carbons and resin: kinetic and isotherm study, Water Res. 43 (2009) 1150-1158.

[35] C.P. Higgins, J.A. Field, C.S. Criddle, R.G. Luthy, Quantitative determination of perfluorochemicals in sediments and domestic sludge, Environ. Sci. Technol. 39 (2005) 3946-3956.

[36] X. Zhong, L. Yu, W. Zhao, Y. Zhang, J. Sun, XPS studies of radiation-induced structural changes in polyvinylidene fluoride, Polym. Degrad. Stab. 39 (1993) 399-402.

[37] M. Marschewski, J. Hirschberg, T. Omairi, O. Höfft, W. Viöl, S. Emmert, W. Maus-Friedrichs, Electron spectroscopic analysis of the human lipid skin barrier: cold atmospheric plasma-induced changes in lipid composition, Exp. Dermatol. 21 (2012) 921-925.

[38] L.D. Nghiem, A. Manis, K. Soldenhoff, A.I. Schäfer, Estrogenic hormone removal from wastewater using NF/RO membranes, J. Membr. Sci. 242 (2004) 37-45.

[39] A.E. Childress, M. Elimelech, Relating nanofiltration membrane performance to membrane charge (electrokinetic) characteristics, Environ. Sci. Technol. 34 (2000) 3710-3716.

[40] F. Wang, K. Shih, Adsorption of perfluorooctane sulfonate (PFOS) and perfluorooctanoate (PFOA) on alumina: Influence of solution $\mathrm{pH}$ and cations, Water Res. 45 (2011) 2925-2930.

[41] J. Cho, G. Amy, J. Pellegrino, Membrane filtration of natural organic matter: comparison of flux decline, NOM rejection, and foulants during filtration with three UF membranes, Desalination 127 (2000) 283-298.

[42] C. Bellona, M. Marts, J.E. Drewes, The effect of organic membrane fouling on the properties and rejection characteristics of nanofiltration membranes, Sep. Purif. Technol. 74 (2010) 44-54.

[43] L.D. Nghiem, D. Vogel, S. Khan, Characterising humic acid fouling of nanofiltration membranes using bisphenol $\mathrm{A}$ as a molecular indicator, Water Res. 42 (2008) 4049-4058.

[44] F. Xiao, M.F. Simcik, J.S. Gulliver, Mechanisms for removal of perfluorooctane sulfonate (PFOS) and perfluorooctanoate (PFOA) from drinking water by conventional and enhanced coagulation, Water Res. 47 (2013) 49-56.

[45] P. Lipp, F. Sacher, G. Baldauf, Removal of organic micro-pollutants during drinking water treatment by nanofiltration and reverse osmosis, Desalin. Water Treat. 13 (2010) 226-237.

[46] L.D. Nghiem, P.J. Coleman, C. Espendiller, Mechanisms underlying the effects of membrane fouling on the nanofiltration of trace organic contaminants, Desalination 250 (2010) 682-687.

[47] M. Sen, A. Manna, P. Pal, Removal of arsenic from contaminated groundwater by membrane-integrated hybrid treatment system, J. Membr. Sci. 354 (2010) $108-113$.

[48] K. Listiarini, D.D. Sun, J.O. Leckie, Organic fouling of nanofiltration membranes: evaluating the effects of humic acid, calcium, alum coagulant and their combinations on the specific cake resistance, J. Membr. Sci. 332 (2009) 56-62.

[49] W.-Z. Yu, H.-J. Liu, T. Liu, R.-P. Liu, J.-H. Qu, Comparison of submerged coagulation and traditional coagulation on membrane fouling: effect of active flocs, Desalination 309 (2013) 11-17. 